\title{
Place Work on a Scale: What Do We Know About the Association Between Employment Status and Weight Loss Outcomes After Bariatric Surgery?
}

\author{
Marleen M. Romeijn ${ }^{1,2}$ (D) Marlies Bongers ${ }^{3,4}$ • Daniëlle D.B. Holthuijsen ${ }^{1} \cdot$ Loes Janssen ${ }^{1} \cdot$ François M.H. van Dielen ${ }^{1}$ • \\ Han J.R. Anema ${ }^{5}$ - Wouter K.G. Leclercq ${ }^{1}$
}

Received: 2 December 2020 / Revised: 23 March 2021 / Accepted: 24 March 2021 / Published online: 21 May 2021

(C) The Author(s) 2021

\begin{abstract}
Despite the initial successful weight loss after bariatric surgery, a significant amount of patients experience weight loss failure and weight regain. Several factors are known to contribute to this, though the impact of employment status is unknown. The objective of this systematic review was to examine the impact of employment status on post-surgical weight loss outcomes. Eight studies were included with a follow-up ranging between 2 and 10 years. Employed patients seemed to present more weight loss $(9.0$ 11.0\% EWL, 1.3-1.6\% BMI loss) compared to unemployed patients, but none of these numbers were statistically significant. Moreover, there were contrasting findings in terms of weight regain. This review may highlight the importance of working status after bariatric surgery and warrants further investigation on this topic.
\end{abstract}

Keywords Bariatric surgery $\cdot$ Metabolic surgery $\cdot$ Employment status · Occupational status

\section{Introduction}

Bariatric surgery has a pivotal role in the treatment of morbid obesity as it effectively reduces weight and obesity related comorbidities $[1,2]$. It has a positive effect on physical functioning, psychological health and employment rate [3-6]. Based on a previous systematic review, employment rate has increased by $20 \%$ and 16-37\% of unemployed patients succeed in finding a job post-surgery (re-employment rate) [5].

Marleen M. Romeijn

m.romeijn@maastrichtuniversity.nl

Marlies Bongers

marlies.bongers@gmail.com

Daniëlle D.B. Holthuijsen

d.holthuijsen@student.maastrichtuniversity.nl

Loes Janssen

Loes.Janssen@mmc.nl

François M.H. van Dielen

F.vandielen@mmc.nl

Han J.R. Anema

h.anema@amsterdamumc.nl
Bariatric surgery has also shown to decrease the rate of absenteeism and presenteeism which is the problem of employees being absent, and being present but not fully functioning because of a medical condition [5].

Non-response refers to the condition when a patient experiences insufficient weight loss, or regains a significant amount of weight [7]. The latter is seen in approximately $20-30 \%$ of patients and may result in the return of obesity related comorbidities and a decreased quality of life [8-10]. The etiology of non-

Wouter K.G. Leclercq

w.leclercq@mmc.nl

Department of Surgery, Máxima Medical Center, Veldhoven, The Netherlands

2 Research School NUTRIM, Department of Surgery, Maastricht University Medical Center, Maastricht, the Netherlands

3 SGBO, Department of Primary and Community Care, Radboud University Medical Center, Nijmegen, The Netherlands

4 ArboNed Occupational Health Service, Utrecht, The Netherlands

5 Department of Public and Occupational Health, Amsterdam Public Health Research, VU University Medical Center, Amsterdam, The Netherlands 
response is multifactorial and includes factors like psychological health and compliance with dietary and exercise regimes [11]. In addition to these factors, it is known that pre-surgical BMI, age, type of surgery (e.g. adjustable gastric banding) and anatomical alterations (e.g. pouch and stoma size) are associated with non-response $[9,11]$. It is unknown if and how employment status contributes to the development of non-response. Despite this, it is well known that unemployment has a negative effect on both physical and mental health [12].

The underlying principle that may drive the relation between work and post-surgical weight loss can be found in the interaction between employment status and lifestyle behavior. Unemployed patients may experience more psychological stress and depression, potentially leading to decreased physical activity and increased caloric consumption [13-15]. Patients who work in shifts tend to have poorer sleep quality and poorer dietary patterns compared to non-shift workers [16]. Certain workstyle and lifestyle behavior may have predisposed the development of chronic illnesses like morbid obesity in the first place and hypothetically, it may counteract weight loss after bariatric surgery $[16,17]$.

In order to maximize or maintain post-surgical weight loss, an understanding of the impact of factors like employment status on weight loss outcomes is essential. Up to now, articles primarily described the impact of bariatric surgery on post-surgical employment rate [5, 6], while fewer articles described the predictive value of pre-surgical employment status on weight loss outcomes. Andersen et al. demonstrated that pre-surgical unemployment was a significant predictor for lower \%excess body mass index loss (EBMIL) in women two years after sleeve gastrectomy (SG) [18]. Additionally, Cadena-Obando et al. found that lacking a fulltime job pre-surgery was a negative predictor for achieving successful weight loss ( $\geq 50 \%$ excess body weight loss) one year after various bariatric procedures [19]. Only the study by Stenberg et al. reported long-term results and these results are in contrast to the abovementioned studies, as the authors found that pre-surgical employment as a professional or technician is independently associated with a lower \%total weight loss (TWL) five years after Roux-en-Y gastric bypass (RYGB) [20].

A common observation is that an employed status is associated with better weight loss outcomes $[18,19]$, though the opposite has also been described [20]. A systematic review comparing long-term outcomes in unemployed and employed patients is lacking and therefore, the objective of this study was to systematically review the literature available on employment status of patients that underwent revisional surgery and their weight loss outcomes.

\section{Methods}

This review complies with the recommendations of the Cochrane Handbook for Systematic Reviews and
Interventions [21], and was recorded according to the PRISMA systematic review guidelines [22].

\section{Eligibility Criteria}

This review included observational studies and randomized controlled trials (RCTs). Studies were considered eligible if they included patients with a Body Mass Index (BMI) $\geq 35 \mathrm{~kg} /$ $\mathrm{m}^{2}$ who had undergone a malabsorptive bariatric procedure (RYGB, SG and biliopancreatic diversion); if they noted employment status pre-surgery or post-surgery, and if they noted change in weight within two to ten years post-surgery. The latter time points were chosen because weight loss reaches its maximum two years after surgery, and weight regain generally occurs in the subsequent years [23]. There were no restrictions regarding the expression of weight, such as change in $\mathrm{kg}$, change in BMI or Excess Weight Loss (EWL). Due to assumed heterogeneity and a lack of information, it was not attempted to further define employment and unemployment. Studies were excluded in case of a restrictive bariatric procedure like adjustable gastric banding and vertical banded gastroplasty because these procedures are not recommended anymore and have little relevance to today's practice [24]. Besides this, studies were excluded in case of endoscopic procedures like gastric plication. Articles that were designed as animal studies, systematic reviews, letter to the editor and conference abstracts were excluded as well.

\section{Systematic Literature Search Methodology}

The systematic search was conducted on May, 2020. The search was conducted in three electronic databases: MEDLINE (new version 2020), EMBASE and The Cochrane Library. There was no restriction regarding publication date. Keywords in the search strategy included [employment] and [bariatric surgery], and their synonyms. The full search strategies for all databases can be found in supplementary table 1 . References within the included articles were screened to retrieve articles that might have been missed.

\section{Study Selection}

RefWorks software was used to manage references and support identification of duplicates. Titles and abstracts were screened on relevance. Full texts were obtained for clarification of eligibility criteria. Reasons for the exclusion of studies were recorded.

\section{Data Extraction}

Data extraction was performed in duplicate by two researchers (MR and DH) and was cross-checked by a third reviewer (LJ). The following study characteristics were extracted from the 
included studies using predefined forms: authors' names, publication year, country, study design, sample size, type of procedure, gender, mean age, mean weight or BMI or EWL, and employment status. In case of missing data, the author of the article was contacted. It was noted whether the employment status was assessed before or after the assessment of weight loss.

\section{Outcome Parameters}

The primary outcome was the difference in weight loss, and subsequent weight regain, between employed and unemployed patients two to ten years after bariatric surgery. When describing these outcomes, the classification of employment status was preferably based on a pre-surgical assessment as this illustrates the direct impact of employment status on weight loss outcomes. If possible, weight loss outcomes were also described for students, retired and disabled patients. Mean differences in weight or BMI were calculated and if possible, standard deviations were extracted. If possible, the percentage of BMI was calculated and the delta $(\Delta)$ BMI was extracted. The formula for calculating $\Delta \% \mathrm{BMI}$ from presurgical to post-surgical was (pre-surgical BMI - postsurgical BMI)/ (pre-surgical BMI) $\times 100 \%$. The following formula was furthermore used for the assessment of weight regain: (post-surgical highest BMI- post-surgical lowest BMI)/ (post-surgical highest BMI) $\times 100 \%$. The advantage of this measurement is that it corrects for baseline differences in BMI, rather than measuring absolute BMI points. The secondary outcome was the difference in (un)employment rate two to ten years after bariatric surgery between pre-surgical employed and unemployed patients.

\section{Quality Appraisal}

In order to assess the methodological quality of the included studies, the Quality in Prognosis Studies (QUIPS) tool was used, as this tool was used. This tool was specifically designed to assess the relationship between the prognostic factor (employment status) and outcome (weight loss and regain) [25]. Two researchers (MR and DH) independently assessed the methodological quality of each study and if consensus could not be reached, inconsistencies were resolved by discussion with a third reviewer (LJ). The following six domains were evaluated: study participations, study attrition, prognostic factor measurement, outcome measurement, study confounding, and statistical analysis and reporting. Each of these domains were eventually rated as low, mediate or high risk of bias.

\section{Results}

The search retrieved 910 bibliographic references and a manual search retrieved two additional articles. A total of 680 articles remained when duplicates were removed. After screening titles and abstracts on relevance, 640 articles were excluded. Full text reading of the 40 remaining articles resulted in the selection of 8 eligible studies. Figure 1 provides a flow diagram of the screening process and inclusion of articles.

\section{Study Characteristics}

Table 1 provides an overview of the included studies. Among the eight included studies, four were retrospective cohort studies $[26,27,29,32]$, three were prospective cohort studies [28, $31,33]$ and one study contained baseline data from a randomized interventional study [30]. The studies add up to 2877 participants with a mean follow-up period of 4.6 years \pm 3.3 . The percentage of females ranged between $70.7 \%$ and $87.8 \%$. The study of Courtney et al. included patients with Roux-en-Y gastric bypass (RYGB), SG, one-anastomosis gastric bypass, as well as gastric banding [26]. The exact amount of patients undergoing each type of procedure is unknown. Two studies specifically mentioned that the procedure was done laparoscopy $[28,29]$, while after contacting the corresponding authors four additional studies appeared to include laparoscopic procedures varying in a rate of $100-75 \%[26,27,29,30]$.

As shown in Table 2, six studies noted employment status pre-surgery and five studies noted this post-surgery. From these six studies, five studies based their classification of employment status when describing weight loss outcomes, on the presurgical assessment [26-30]. In the other three included studies is it unknown whether the employment status used in the description of weight loss outcomes is assessed prior or after to the assessment of weight loss [31-33]. Four studies used self-report questionnaires for the evaluation of employment status [26, 27, $29,33]$, while patient files were also commonly used [26, 28, 29]. Three studies described the rate of retired and/or disabled patients separately $[26,28,29]$. Definitions of employment and unemployment were given in only two studies. Mancini et al. classified employed as full-time employed including students and maternity leave [27]; unemployed was classified as parttime employed, temporary impairment and job seeking. Reid et al. described employed and unemployed when this lasted for a minimum of one year. Additionally, unemployed also included retired and disabled participants [31].

\section{Quality of the Studies (Risk of Bias)}

Results for risk of bias were retrieved using the QUIPS tool as shown in Table 3. Overall, four studies were judged as "moderate" risk of bias $[26,28,29,33]$ and four studies were judged as "low" risk of bias [27, 30-32]. Due to a lost to follow-up of $39 \%$ after one year [28] and 50\% after two years [29], two studies were judged as having a "moderate" risk of attrition bias. Furthermore, four studies were considered to have a "moderate" risk of bias concerning prognostic factor 
Fig. 1 PRISMA flow diagram for study selection. LABG,

laparoscopic adjustable gastric banding; VBG, vertical banded gastroplasty

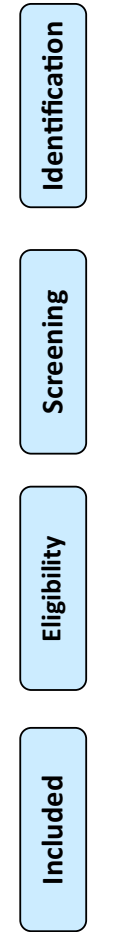

measurement, due to the lack of a questionnaire when evaluating employment status [26, 28, 29, 33]. An important source of confounding was based on the finding that unemployed patients experienced more comorbidities [26] and used more psychopharmaceutical drugs [30].

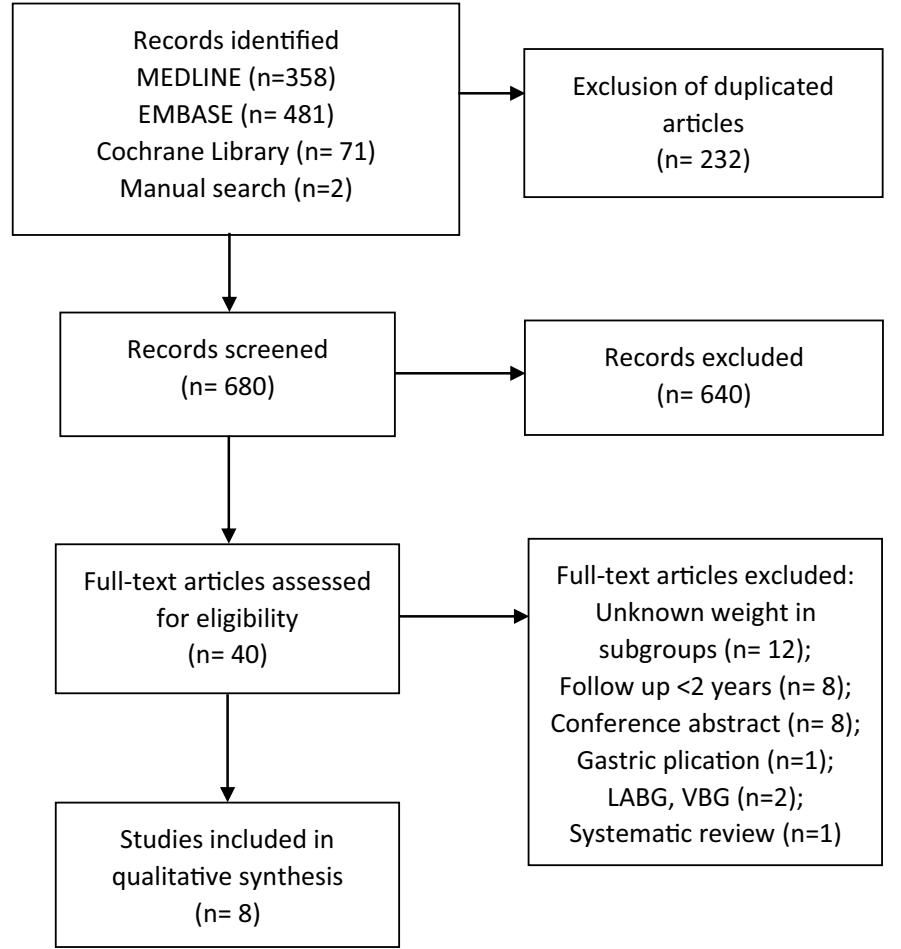

Weight Loss Outcomes

Based on the studies that expressed weight loss in \%EWL, employed patients lost $66.0 \%$ (pre-surgical assessed), $65.0 \%$ (post-surgical assessed) and $68.6 \%$ (post-surgical assessed)

Table 1 Study characteristics

\begin{tabular}{|c|c|c|c|c|c|c|}
\hline Author and year & Country & Study design & $\begin{array}{l}\text { Number of subjects } \\
\text { (female gender) }\end{array}$ & $\begin{array}{l}\text { Age of } \\
\text { subjects }^{1}\end{array}$ & Surgical procedure & $\begin{array}{l}\text { Follow-up } \\
\text { (years) }\end{array}$ \\
\hline $\begin{array}{l}\text { Courtney et al. } 2018 \\
{[26]}\end{array}$ & UK & Retrospective cohort & $\begin{array}{l}1011 \\
(762)\end{array}$ & $47(18-78)$ & $\begin{array}{l}\text { Laparoscopic, multiple } \\
\text { bariatric techniques }^{2}\end{array}$ & 2 \\
\hline $\begin{array}{l}\text { Mancini et al. } 2018 \\
\text { [27] }\end{array}$ & France & Retrospective cohort & $\begin{array}{r}238 \\
(195)\end{array}$ & $40(34-48)$ & $\begin{array}{l}\text { Laparoscopic RYGB (64.7\%) } \\
\text { SG }(35.3 \%)\end{array}$ & 2 \\
\hline $\begin{array}{l}\text { Jambhekar et al. } 2018 \\
{[28]}\end{array}$ & USA & Prospective cohort & $\begin{array}{r}713 \\
(622)\end{array}$ & $41.7 \pm 11.2$ & Laparoscopic SG & 2 \\
\hline $\begin{array}{l}\text { Keith et al. } 2018 \\
\text { [29] }\end{array}$ & USA & Retrospective cohort & $\begin{array}{r}586 \\
(461)\end{array}$ & $43(36-51)$ & Laparoscopic RYGB & 9 \\
\hline $\begin{array}{l}\text { Hanvold et al. } 2015 \\
\text { [30] }\end{array}$ & Norway & $\begin{array}{l}\text { Randomized lifestyle } \\
\text { inter-vention study }\end{array}$ & $\begin{array}{r}165 \\
(123)\end{array}$ & $44 \pm 8.6$ & Laparoscopic RYGB & 2 \\
\hline $\begin{array}{l}\text { Reid et al. } 2018 \\
\text { [31] }\end{array}$ & Canada & Prospective cohort & $\begin{array}{c}48 \\
(36)\end{array}$ & $50.7 \pm 9.4$ & Laparoscopic RYGB ${ }^{3}$ & 10 \\
\hline $\begin{array}{l}\text { Velcu et al. } 2005 \\
\text { [32] }\end{array}$ & USA & Retrospective cohort & $\begin{array}{c}41 \\
(36)\end{array}$ & $32.4 \pm 3.6$ & Open RYGB & 5 \\
\hline $\begin{array}{l}\text { Diaz- Guerra et al. } 2005 \\
\text { [33] }\end{array}$ & Spain & Prospective cohort & $\begin{array}{c}75 \\
(53)\end{array}$ & 39 & Open BPD of Larrad & 5 \\
\hline
\end{tabular}

Abbreviations $B M I$ Body Mass Index, $B P D$ biliopancreatic diversion, $R Y G B$ Roux-en-Y gastric bypass, SG Sleeve Gastrectomy, UK United Kingdom, USA United States of America

${ }^{1}$ Expressed in mean with standard deviation or mean with range

${ }^{2}$ Included RYGB, SG, one-anastomosis gastric bypass and gastric banding

${ }^{3}$ Majority of patients were done laparoscopically $( \pm 75 \%)$ 
[26, 31]. Additionally, unemployed patients lost $55.0 \%$ (presurgical assessed), $70.8 \%$ (pre-surgical assessed), 56.0\% (post-surgical assessed) and 78.9\% (post-surgical assessed) $[26,27,31]$. This indicates a difference of $11.0 \%$ EWL in favor of pre-surgical employed [26], 9.0\% EWL in favor of postsurgical employed [26] and 10.3\% EWL in favor of postsurgical unemployed patients [31]. In addition, two studies used cut-off scores of 50\% EWL to define success and failure [30, 33]. These studies found that, in patients with successful weight loss, the rate of unemployment ranged between $33.6-42.4 \%$; additionally, in patients with not successful weight loss, the rate unemployment ranged between $32.1-66.6 \%$ [30, 33]. These rates were not described for employed patients.

Based on the studies that used BMI, employed patients lost 22.5 and 24.9 points, while the unemployed patients lost 13.0, 23.6 and 22.1 points [27, 31, 32]. Reid et al. reported a greater BMI loss by post-surgical employed patients (2.8 BMI points), while Velcu et al. reported a greater BMI loss by unemployed patients (1.1 BMI points) [31, 32]. These findings were not statistically significant. When calculating \%BMI loss, employed patients lost $1.3 \%$ (45.3\% vs. $44.0 \%$ ) and $1.6 \%$ (44.0\% vs. $42.4 \%)$ more compared to unemployed patients $[31,32]$.

Only one study expressed weight loss in $\mathrm{kg}$ which was a maximum of $32.4 \mathrm{~kg}$ in pre-surgical employed patients and $33.5 \mathrm{~kg}$ in pre-surgical unemployed patients [28]. The authors described that an employed status was almost uniformly associated with more weight loss up to two years post-surgery [28].

\section{Weight Regain Outcomes}

Looking at studies that assessed weight regain and \%BMI was extracted, post-surgical employed patients gained $5.0 \%$ and $17.1 \%$, while post-surgical unemployed patients gained $1.2 \%$ and $15.4 \%$ five and nine/ten years after surgery, respectively $[31,32]$. When expressed in absolute BMI points, this amounted a difference of 1.1 points between the groups and was not statistically significant. Jambhekar et al. found that presurgical unemployed patients gained slightly more weight compared to employed patients $(5.4 \mathrm{~kg}$ versus $3.8 \mathrm{~kg}$ ) two years after surgery [28]. Moreover, Keith et al. found that pre-surgical unemployed patients presented $4.4 \%$ more weight regain ( $>15 \%$ regain one year post-surgery) compared to employed patients [29]. Logistic regression analysis however, revealed that pre-surgical employment status was of no predictive value on weight regain (odds ratio 1.21, $p$ value 0.482) [29].

\section{Change in Employment Status}

The amount of pre-surgical employed patients ranged between $34.1 \%$ and $80.0 \%[26-30,32]$, and the amount of pre-surgical unemployed patients ranged between $7.0 \%$ and $65.8 \%[29$, $26,28,30,32]$. The amount of post-surgical employed patients ranged between $39.6 \%$ and $83.6 \%$ [26, 27, 30-32], while for the post-surgical unemployed patients this was $21 \%$ and $60.9 \%$ [26, 30-32].

Four studies assessed employment status pre- and post-surgery, thereby making it possible to detect changes. When focusing on the studies with a two year follow-up, employment rate increased by $4.4 \%$ [30], 10.4\% [26] and $17.2 \%$ [27], while unemployment rate decreased by $15.6 \%$ [26]. Two studies found that the increase in employment rate was statistically significant [26, 27], and also one study found that the decrease in unemployment rate was statistically significant [26]. Five years after surgery employment rate increased by $9.8 \%$ and the unemployment rate decreased by $9.7 \%$. Nevertheless, this lacked statistical significance [32].

\section{Discussion}

Very little is known about the interplay of socioeconomic factors like employment status and their effect on weight loss after bariatric surgery, and how they interfere with the development of non-response. This systematic review aimed to investigate the impact of employment status on post-bariatric surgical weight loss outcomes. In summary, this study found that employed patients experienced more weight loss $(9.0$ $11.0 \%$ EWL [26], 1.3-1.6\% BMI [31, 32]) two to three years after surgery compared to unemployed patients; however, these findings are not consistent across the included studies and lacked statistical significance $[28,31]$. It can be debated whether these amounts of weight loss have sufficient clinical relevance. Nonetheless, it is well known that more weight loss is associated with better clinical outcomes such as an improved health related quality of life and physical fitness [34, 35].

An obvious finding that emerges from this study is that various measurements were used when expressing weight loss (e.g. kg, \%EWL, BMI), making a clear comparison between employed and unemployed patients difficult. The diversity in measurements used, as well as the accuracy of these measurements should be criticized. Lost BMI points and $\mathrm{kg}$ are highly dependent on their baseline measurement which may give an under- or overestimation of the actual weight loss. This may have been applicable when comparing weight loss reported by Reid et al. and Velcu et al. where there was a difference in baseline BMI [31, 32]. In order to overcome this, we calculated the percentage of BMI which is a more commonly used measurement in articles describing post-surgical weight loss outcomes [36]. Besides the inaccuracy of absolute numbers, it is well known that $\% \mathrm{EWL}$ is a suboptimal measurement as this is being influenced too much by common differences in baseline BMI $[37,38]$. Percentage TWL has been suggested as the most accurate measurement, though none of the included studies used this measurement. 


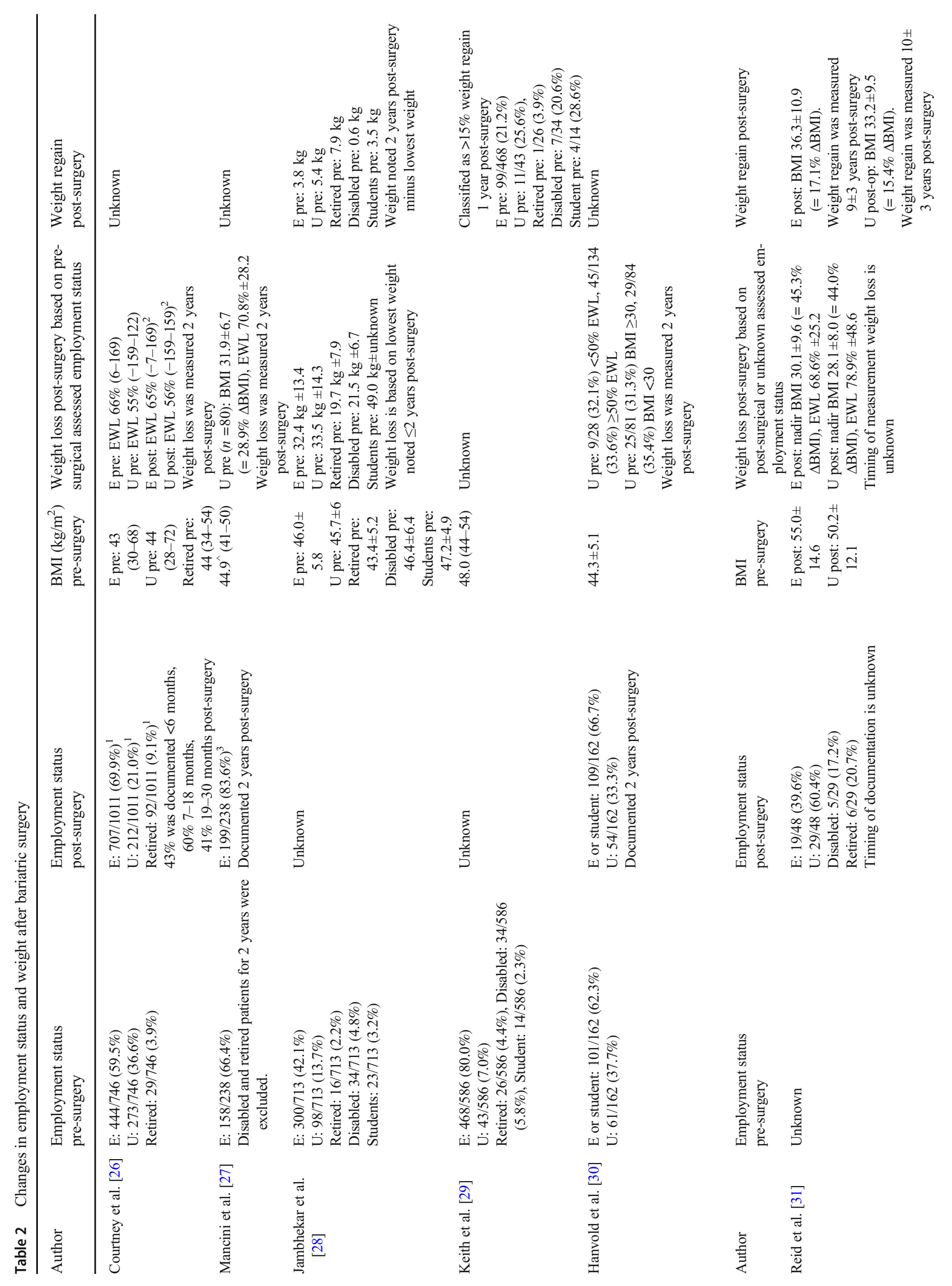




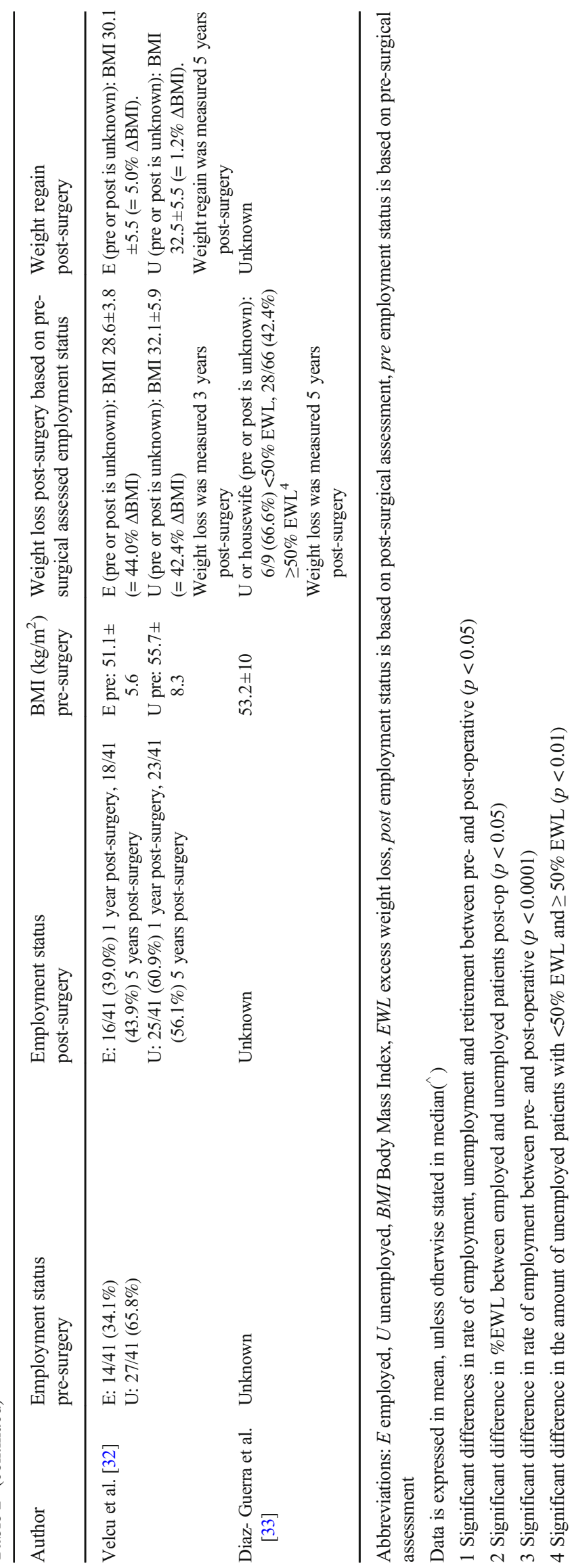


Table 3 Assessment of risk of bias using the 'Quality Assessment in Prognostic Studies' (QUIPS) tool

\begin{tabular}{|c|c|c|c|c|c|c|c|}
\hline Author & $\begin{array}{l}\text { Study } \\
\text { participation }\end{array}$ & $\begin{array}{l}\text { Study } \\
\text { attrition }\end{array}$ & $\begin{array}{l}\text { Prognostic factor } \\
\text { measurement }\end{array}$ & $\begin{array}{l}\text { Outcome } \\
\text { measurement }\end{array}$ & $\begin{array}{l}\text { Study } \\
\text { confounding }\end{array}$ & $\begin{array}{l}\text { Statistical } \\
\text { analysis } \\
\text { and reporting }\end{array}$ & Overall \\
\hline $\begin{array}{l}\text { Courtney et al. } 2018 \\
{[26]}\end{array}$ & Moderate & Low & Moderate & Low & High & Moderate & Moderate \\
\hline $\begin{array}{l}\text { Mancini et al. } 2018 \\
\text { [27] }\end{array}$ & Low & Low & Low & Low & Moderate & Low & Low \\
\hline $\begin{array}{l}\text { Jambhekar et al. } 2018 \\
\text { [28] }\end{array}$ & Low & Moderate & Moderate & Moderate & Moderate & Low & Moderate \\
\hline $\begin{array}{l}\text { Keith et al. } 2018 \\
\text { [29] }\end{array}$ & Low & Moderate & Moderate & Moderate & Moderate & Low & Moderate \\
\hline $\begin{array}{l}\text { Hanvold et al. } 2015 \\
\text { [30] }\end{array}$ & Low & Low & Low & Low & Moderate & Low & Low \\
\hline $\begin{array}{l}\text { Reid et al. } 2018 \\
{[31]}\end{array}$ & Low & Low & Low & Low & Low & Low & Low \\
\hline $\begin{array}{l}\text { Velcu et al. } 2005 \\
{[32]}\end{array}$ & Low & Low & Low & Low & Moderate & Low & Low \\
\hline $\begin{array}{l}\text { Diaz- Guerra et al. } 2005 \\
\text { [33] }\end{array}$ & Moderate & Low & Moderate & Low & Moderate & Moderate & Moderate \\
\hline
\end{tabular}

Low low risk of bias, Moderate moderate risk of bias, High high risk of bias

Level of risk of bias was determined by judgment of the prompting items belonging to each assessed domain

There are four explanations for the finding that employed patients may experience more weight loss. Firstly, employed patients may be greater committed to health promoting behavior $[13,14]$, thereby positively affecting eating habits, physical activities and subsequent weight loss. Reid et al. demonstrated that post-surgical employed patients performed 1591 more steps per day compared to unemployed patients [31]. Additionally, Courtney et al. showed greater improvements in functional status of pre-surgical employed patients than unemployed patients (35.7\% vs. $29.2 \%$ ) [26]. Though the direction of causality between functional status/physical activity and weight loss is uncertain, it does implicate the importance of employment in post-bariatric patients. A second explanation is that unemployment is related to a lower socioeconomic status, and a lower socioeconomic status is associated with less post-bariatric weight loss [20,39]. In detail, inferior weight loss have been described in first-generation immigrants, residents in larger cities, patients with low income and patients who receive social security disability $[20,28$, 39]. A third explanation for the aforementioned finding is that employed patients are more likely to be adherent to follow-up appointments after bariatric surgery, and attendance to these appointments is associated with better long-term weight loss outcomes [17, 40,41]. A fourth explanation may be that employed patients experience more routineness in daily life. Because of this, it may take less effort to adjust a new lifestyle, for example learning new eating patterns. This explanation broadly supports the finding that being employed, either part-time or fulltime is associated with less frequent unhealthy eating compared to the unemployed [17]. The finding from Jambhekar et al. that students experienced more weight loss compared to retired patients may underline this theory as students attend school activities which gives them a certain routineness [28]. Employed patients may also show, as result of long working hours, irregular work schedules and thereby have less daily or weekly routineness [42].

Based on the studies that reported weight regain, employed patients gained 1.7-3.8\% more BMI than unemployed patients five to ten years after surgery $[31,32]$, though the opposite was also found (1.6 kg more regain by unemployed patients) [28]. These results lacked any statistical significance. It is difficult to explain why an employed patient would gain more weight and furthermore, a comparison with other studies is hard as these studies lack a sufficient follow-up period to detect weight regain. This warrants further research to obtain more information about the impact of employment status on losing and maintaining weight post-surgery.

This study found that the employment rate increased by 4.4-17.2\%, while the unemployment rate decreased by $15.6 \%$ after bariatric surgery. A note of caution is necessary as employment and unemployment rates showed large baseline variety and clarification lacked frequently (e.g. distinction between fulltime and part-time). The improvement in employment rate we found is in line with a previous systematic review which overlapped two studies [5, 30, 32]. The observed increase in employment might be explained in this way: weight loss caused by bariatric surgery results in patients becoming more healthy $[34,35]$, and patients with a better health condition are more likely to find a job as opposed to jobseekers with a poorer health condition [12].

We acknowledge that this review has an important limitation due to its differences in the assessment of employment status at 
the moment of describing weight loss outcomes. As far as possible, we presented outcomes based on a pre-surgical assessment of employment status and indicated if this was not the case or uncertain. Despite this, it can be debated whether we are looking at the direct impact of employment status on weight loss outcomes or a reverse relation (i.e., impact of weight loss on employment status). Within this relationship, other variables such as the type of job, type of insurance, level of education and neighborhood status may possible interfere. Unfortunately, these variables were very limitedly described in the included studies, highlighting the need for future studies to concentrate on these variables.

Other limitations of this study can be found in methodological issues. To start, the quality of the studies was limited with four studies being assessed as a moderate risk of bias. Selection bias may have been introduced in two studies as it seemed that highly motivated patients returned to follow-up appointments, thereby affecting the documentation of weight and employment status [26, 28]. Furthermore, three studies lacked self-report questionnaires but referred to routinely collected documentation when evaluating employment status, thereby introducing information bias [26, 28, 29]. Multiple studies faced confounding as unemployed patients suffered from functional impairment, co-morbidities and mental health disorders, contributing to their unemployment [26, 33]. None of the studies sufficiently accounted for potential confounders including age, gender, personality disorders, pre-surgical weight and physical activity, while these factors have consistently been associated with weight loss outcomes. Besides this, information lacked about the job type including shift work and a sedentary job, though both are related to obesity [16]. Lastly, it should be mentioned that different surgical procedures were used (laparoscopic versus open; restrictive versus malabsorptive) and it was not always clear how these procedures were distributed in the study cohort [26].

The question rises how the results of this review can be used in the daily practice. We should first be aware of the bidirectional interaction between employment status and post-bariatric weight loss outcomes. We should concentrate on identifying a patients' employment status in a pre-surgical setting, for example during screening for bariatric surgery, and subsequently in a postsurgical setting. All patients should be motivated and encouraged by health care professionals in bariatric centers to either become or stay employed. A collaboration with occupational health physicians could be beneficial for advising employed patients how they return to work, and for unemployed patients how they acquire a job. Further research should be done to see if the joint effort with the occupational health department is feasible.

\section{Conclusion}

This systematic review showed that an employed status could be beneficial for losing weight after bariatric surgery, though this finding is subjected to heterogeneity in included studies and a lack of statistical significance. The results may implicate that employed patients should be encouraged by health care professionals to return to work and that unemployed patients should be supported to return to labor market. More knowledge is needed to fully understand the interplay between employment status, job type, socioeconomic factors and weight loss outcomes after bariatric surgery.

Abbreviations BMI, Body mass index; EBMIL, Excess body mass index loss; EWL, Excess weight loss; Kg, Kilograms; RCT, Randomized controlled trials; RYGB, Roux-en-Y gastric bypass; SG, Sleeve gastrectomy; TWL, Total weight loss; QUIPS, Quality in Prognosis Studies.

Supplementary Information The online version contains supplementary material available at https://doi.org/10.1007/s11695-021-05388-9.

\section{Declarations}

Statement of Human and Animal Rights/Ethical Approval This paper does not contain any studies with human participants or animals performed by any of the authors.

\section{Statement of Informed Consent Informed Consent does not apply.}

Conflict of Interest All authors declare that they have no conflict of interest. No specific grant or funding was received for this research.

Open Access This article is licensed under a Creative Commons Attribution 4.0 International License, which permits use, sharing, adaptation, distribution and reproduction in any medium or format, as long as you give appropriate credit to the original author(s) and the source, provide a link to the Creative Commons licence, and indicate if changes were made. The images or other third party material in this article are included in the article's Creative Commons licence, unless indicated otherwise in a credit line to the material. If material is not included in the article's Creative Commons licence and your intended use is not permitted by statutory regulation or exceeds the permitted use, you will need to obtain permission directly from the copyright holder. To view a copy of this licence, visit http://creativecommons.org/licenses/by/4.0/.

\section{References}

1. Buchwald H, Avidor Y, Braunwald E, et al. Bariatric surgery: a systematic review and meta-analysis. J Am Med Assoc. 2004;292(14):1724-37.

2. Puzziferri N, Roshek TB, Mayo HG, et al. Long-term follow-up after bariatric surgery: a systematic review. JAMA. 2014;312(9): 934-42. https://doi.org/10.1001/jama.2014.10706.

3. Sarwer DB, Wadden TA, Moore RH, et al. Preoperative eating behavior, postoperative dietary adherence, and weight loss after gastric bypass surgery. Surg Obes Relat Dis. 2008;4(5):640-6.

4. Steele T, Cuthbertson DJ, Wilding JPH. Impact of bariatric surgery on physical functioning in obese adults. Obes Rev. 2015;16(3): 248-58.

5. Vayr F, Charras L, Savall F, et al. The impact of bariatric surgery on employment: a systematic review. Bariatric Surg Pract Patient Care. 2018;13(2):54-63. https://doi.org/10.1089/bari.2018.0014. 
6. Sharples A, Sharples A, Cheruvu C, et al. Systematic review and meta-analysis of occupational outcomes after bariatric surgery. Obes Surg. 2017;27(3):774-81. https://doi.org/10.1007/s11695016-2367-x.

7. Bonouvrie DS, Uittenbogaart M, Luijten AAPM, et al. Lack of standard definitions of primary and secondary (non)responders after primary gastric bypass and gastric sleeve: a systematic review. Obes Surg. 2019;29(2):691-7. https://doi.org/10.1007/s11695018-3610-4.

8. Karmali S, Brar B, Shi X, et al. Weight recidivism post-bariatric surgery: a systematic review. Obes Surg. 2013;23(11):1922-33. https://doi.org/10.1007/s11695-013-1070-4.

9. Hameed S, Salem V, Tan TM, et al. Beyond weight loss: establishing a postbariatric surgery patient support group-what do patients want? J Obes. 2018;2018:8419120.

10. Jirapinyo P, Abu Dayyeh BK, Thompson CC. Weight regain after roux-en-Y gastric bypass has a large negative impact on the bariatric quality of life index. BMJ Open Gastroenterol. 2017;4(1): e000153. https://doi.org/10.1136/bmjgast-2017-000153.

11. Toussi R, Fujioka K, Coleman KJ. Pre- and postsurgery behavioral compliance, patient health, and postbariatric surgical weight loss. Obesity. 2009;17(5):996-1002.

12. Hult M, Lappalainen K, Saaranen TK, et al. Health-improving interventions for obtaining employment in unemployed job seekers. Cochrane Database Syst Rev. 2020;1(1):CD013152. Published 2020 Jan 8. https://doi.org/10.1002/14651858.CD013152.pub2.

13. Colman G, Dave D. Unemployment and health behaviors over the business cycle: a longitudinal view. South Econ J. 2018;85(1):93120.

14. Dave DM, Kelly IR. How does the business cycle affect eating habits? Soc Sci Med. 2012;74(2):254-62.

15. Wurtman JJ. Depression and weight gain: the serotonin connection. J Affect Disord. 1993;29(2-3):183-92.

16. Hulsegge G, van Mechelen W, Paagman H, et al. The moderating role of lifestyle, age, and years working in shifts in the relationship between shift work and being overweight. Int Arch Occup Environ Health. 2020;93(6):697-705. https://doi.org/10.1007/s00420-02001519-4.

17. Rosenthal L, Carroll-Scott A, Earnshaw VA, et al. The importance of full-time work for urban adults' mental and physical health. Soc Sci Med. 2012;75(9):1692-6. https://doi.org/10.1016/j.socscimed. 2012.07.003.

18. Andersen JR, Aadland E, Nilsen RM, et al. Predictors of weight loss are different in men and women after sleeve gastrectomy. Obes Surg. 2014;24(4):594-8. https://doi.org/10.1007/s11695-0131124-7.

19. Cadena-Obando D, Ramírez-Rentería C, Ferreira-Hermosillo A, et al. Are there really any predictive factors for a successful weight loss after bariatric surgery? BMC Endocr Disord. $2020 \mathrm{Feb} 5 ; 20$ (1): 20. https://doi.org/10.1186/s12902-020-0499-4.

20. Stenberg E, Näslund I, Persson C, et al. The association between socioeconomic factors and weight loss 5 years after gastric bypass surgery. Int J Obes. 2020;44(11):2279-90. https://doi.org/10.1038/ s41366-020-0637-0.

21. Higgins JPT, Thomas J, Chandler J, Cumpston M, Li T, Page MJ, Welch VA (editors). Cochrane handbook for systematic reviews of interventions version 6.0 (updated July 2019). Cochrane, 2019.

22. Moher D, Liberati A, Tetzlaff J, et al. PRISMA group. Preferred reporting items for systematic reviews and meta-analyses: the PRISMA statement. PLoS Med. 2009;6(7)

23. Sjöström L. Review of the key results from the Swedish obese subjects (SOS) trial - a prospective controlled intervention study of bariatric surgery. J Intern Med. 2012;273(3):219-34. https:// doi.org/10.1111/joim.12012.

24. Angrisani L, Santonicola A, Lovino P, et al. IFSO worldwide survey 2016: primary, endoluminal, and revisional procedures. Obes Surg. 2016, 28(12)

25. Hayden JA, van der Windt DA, Cartwright JL, et al. Assessing bias in studies of prognostic factors. Ann Intern Med. 2013;158(4):280 6.

26. Courtney MJ, Mahawar K, Burnell P, et al. Occupational outcomes of bariatric surgery-do the employed return to work, and do the unemployed find work? Quality in bariatric surgery. Obes Surg. 2017;27(Supplement 1):349.

27. Mancini A, Borel A, Coumes S, et al. Bariatric surgery improves the employment rate in people with obesity: 2-year analysis. Surg Obes Relat Dis: official Journal of the American Society for Bariatric Surgery. 2018;14(11):1700-4.

28. Jambhekar A, Maselli A, Robinson S, et al. Demographics and socioeconomic status as predictors of weight loss after laparoscopic sleeve gastrectomy: a prospective cohort study. Int J Surg. 2018;54(Pt A):163-9. https://doi.org/10.1016/j.ijsu.2018.04.025.

29. Keith Jr C, Gullick A, Feng K, et al. Predictive factors of weight regain following laparoscopic roux-en-Y gastric bypass. Surg Endosc. 2018;32(5):2232-8. https://doi.org/10.1007/s00464-0175913-2.

30. Hanvold SE, Løken EB, Paus SF, et al. Great health benefits but no change in employment or psychopharmaceutical drug use 2 years after roux-en-Y gastric bypass. Obes Surg. 2015;25(9):1672-9.

31. Reid RER, Jirasek K, Carver TE, et al. Effect of employment status on physical activity and sedentary behavior long-term post-bariatric surgery. Obes Surg. 2018;28(3):869-73.

32. Velcu LM, Adolphine R, Mourelo R, et al. Weight loss, quality of life and employment status after roux-en-Y gastric bypass: 5-year analysis. Surg Obes Relat Dis: official Journal of the American Society for Bariatric Surgery. 2005;1(4):413-6. discussion 417

33. Diaz-Guerra C, Jiménez A. Analysis of weight loss with the biliopancreatic diversion of larrad: absolute failures or relative successes? Obes Surg. 2002;12(2):249-52. https://doi.org/10.1381/ 096089202762552719.

34. Poelemeijer YQM, van der Knaap ETW, Marang-van de Mheen PJ. Measuring quality of life in bariatric surgery: a multicentre study. Surg Endosc. et al, 2020;34(12):5522-32.

35. Monpellier VM, Janssen IMC, Antoniou EE, et al. Weight change after roux-en Y gastric bypass, physical activity and eating style: is there a relationship? Obes Surg. 2019;29(2):526-33.

36. Mocanu V, Nasralla A, Dang J, et al. Ongoing inconsistencies in weight loss reporting following bariatric surgery: a systematic review. Obes Surg. 2019;29(4):1375-87. https://doi.org/10.1007/ s11695-018-03702-6.

37. van de Laar AW, Nienhuijs SW, Apers JA, et al. The Dutch bariatric weight loss chart: a multicenter tool to assess weight outcome up to 7 years after sleeve gastrectomy and laparoscopic roux-en-Y gastric bypass. Surg Obes Relat Dis. 2019;15(2):200-10. https:// doi.org/10.1016/j.soard.2018.11.024.

38. Corcelles R, Boules M, Froylich D, et al. Total weight loss as the outcome measure of choice after roux-en-Y gastric bypass. Obes Surg. 2016;26(8):1794-8. https://doi.org/10.1007/s11695-0152022-y.

39. Carden A, Blum K, Arbaugh CJ, et al. Low socioeconomic status is associated with lower weight-loss outcomes 10-years after roux-enY gastric bypass. Surg Endosc. 2019 Feb;33(2):454-9. https://doi. org/10.1007/s00464-018-6318-6.

40. Wheeler E, Prettyman A, Lenhard MJ, et al. Adherence to outpatient program postoperative appointments after bariatric surgery. 
Surg Obes Relat Dis. 2008;4(4):515-20. https://doi.org/10.1016/j. soard.2008.01.013.

41. Larjani S, Spivak I, Hao Guo M, et al. Preoperative predictors of adherence to multidisciplinary follow-up care postbariatric surgery. Surg Obes Relat Dis. 2016;12(2):350-6. https://doi.org/10.1016/j. soard.2015.11.007.
42. Gough M. A couple-level analysis of participation in physical activity during unemployment. SSM - Popul Health. 2017;3(C):294 304. https://doi.org/10.1016/j.ssmph.2017.03.001.

Publisher's Note Springer Nature remains neutral with regard to jurisdictional claims in published maps and institutional affiliations. 